\title{
PENGATURAN ULANG ZONING RUANG UNTUK MENGETAHUI EFISIENSI BEBAN AC DAN PENCAHAYAAN PADA SUMMARECON OFFICE, JAKARTA
}

\author{
Tantri Oktavia \\ (Email: tantri_oktavia@yahoo.com) \\ Program Studi Desain Interior \\ Fakultas Seni Rupa dan Desain \\ Universitas Kristen Maranatha \\ Jl. Prof. Drg. Surya Sumantri No 65, Bandung, Indonesia
}

\begin{abstract}
ABSTRAK
Bangunan salah satu tempat manusia beraktivitas tidak terlepas dari penggunaan energi, khususnya energi listrik. Dengan adanya fenomena global warming memberikan dampak yang cukup signifikan terhadap penggunaan energi listrik di dalam bangunan. Penggunaan lampu dan air conditioning sudah menjadi kebutuhan pokok dalam sebuah bangunan untuk menciptakan kenyamanan penggunanya. Besarnya energi listrik yang dipergunakan dipengaruhi pula oleh perancangan bangunan dan interiornya. Bangunan kantor sewa bertingkat banyak adalah salah satu bangunan yang cukup banyak dibuat di kota- kota besar. Bangunan ini biasanya dibuat oleh sebuah perusahaan besar untuk dijadikan image bagi perusahaannya. Dari bangunan tersebut, sebagian besar lahannya akan disewakan ke kantor-kantor kecil lain. Dengan demikian, selain image fasilitas pelayanan dan harga sewa mempengaruhi laku atau tidaknya area kantor yang disewakan. Besarnya konsumsi energi listrik di dalam bangunan merupakan salah satu masalah besar yang menentukan harga sewa, karena berpengaruh pada operasional cost yang menjadi beban di setiap bulannya. Perencanaan ulang interior yang berkaitan dengan manajemen energi merupakan salah satu cara agar bangunan yang telah beroperasi dapat mengefisiensikan penggunaan energi. Penghawaan atau AC dan penggunaan lampu merupakan beban terbesar dalam sebuah bangunan yang dapat dilakukan efisiensi energi. Oleh karena itu, penelitian ini dilakukan berupa pendataan sumber panas yang berada dan masuk ke dalam bangunan beserta pergerakan sinar matahari untuk memanfaatkan pencahayaan alami. Berdasarkan data ini akan dilakukan pengendalian untuk mengurangi panas dan memaksimalkan pencahayaan alami. Metode Sun Path akan dipergunakan untuk mengetahui pergerakan sinar matahari yang masuk ke dalam bangunan sepanjang tahun dan metode OTTV (Overall Thermal Transfer Value) untuk mengetahui besarnya panas yang masuk ke dalam bangunan melalui fasade bangunan. Hasil analisis dengan menggunakan kedua metode di atas dipergunakan sebagai dasar untuk melakukan perencanaan interior berupa penzoningan ulang ruang.
\end{abstract}

Kata Kunci: beban AC; beban pencahayaan; efisiensi energi; kantor sewa; pengaturan zoning

\section{ABSTRACT}

People always work with using energy especially electricity. Global warming gives big impact to electricity consumption. Lighting and air conditioning is important thing to improve a human comfort inside the building. Architecture and interior design give impact to building's energy consumption. Many high rise rent office are build at the city. High rise office is a branding for the company to look good. Not all building will use for the company, but share with other. The Office design must be good, comfort and good service and cheap for the rent. Energy consumption for operational cost is important thing to decrease rent cost. The solution to make energy efficient is make new design for interior. Air conditioning and lighting is a big part in energy comsumption. Designer must calculate the energy use to decrease an energy comsumption from AC and lighting. This research will collect all heat data from interior and from outdoor penetration. This research use Sun Path Method to know when the buildings have a biggest heat from sunlight everyday. The use of OTTV method (Overall Thermal Tranfer Value) to check a heat value transfer from the façade material. The result will help the designer to make zoning and will make a building efficient 
Keyword: cooling load; energy efficient; lighting load; rental office; zoning

\section{PENDAHULUAN}

Konsumsi energi listrik terus meningkat setiap tahunnya, keadaan ini sebenarnya sudah diperingatkan sejak lama namun belum banyak perencana dan pemilik bangunan mempedulikannya. Beberapa tahun terakhir muncul gerakan masyarakat yang mengangkat fenomena Climate Change, Global warming dan yang serupa dengan hal tersebut dengan tujuan menyadarkan masyarakat tentang penggunaan energi.

Permasalahan efisiensi energi ini bukanlah hal yang mudah dilakukan. Banyak orang tidak peduli karena merasa masih mampu membayar listrik, akan tetapi hal ini berdampak besar pada bangunan komersial, karena berpengaruh terhadap biaya operasional bangunan yang berhubungan dengan harga sewa gedung.

Efisiensi energi hanya dapat dilakukan pada perencanaan awal bangunan, tidak pada bangunan yang telah beroperasional. Pada bangunan yang telah beroperasional efisiensi energi bisa disiasati melalui adaptasi dari perilaku pemakai bangunan. Namun tidak semua pemakai bangunan dapat melakukan adaptasi dengan usaha efisiensi energi di atas., karena efisiensi energi pada bangunan bisa mengakibatkan

berkurangnya kenyamanan bangunan, yang akan berpengaruh pada produktivitas kerja dan pada akhirnya akan merugikan pemilik bangunan.

Keadaan udara di kota besar yang panas dan berpolusi menjadikan pendingin ruangan-AC menjadi sangat diperlukan untuk menciptakan kenyamanan di dalam gedung terutama pada keseluruhan ruang bangunan tinggi. Oleh karena itu yang perlu diperhatikan adalah pengaturan ulang untuk efisiensi bangunan sehingga dapat menekan biaya tanpa mengurangi kenyamanan pengguna bangunan. Penyebab suatu bangunan menjadi panas dan menambah beban pendinginan AC adalah penggunaan peralatan yang mengeluarkan panas, lampu, manusia dan panas dari luar bangunan yang masuk melalui dinding eksterior dan atap. Beban panas terbesar dalam suatu bangunan yaitu antara jam 10.00 hingga 16.00 dengan beban sebesar 80-100 \%, sehingga dapat dikatakan bangunan kantor mengalami beban panas terbesar bersamaan dengan jam operasional kantor.

Bangunan kantor sewa bertingkat banyak membutuhkan penghematan energi karena menggunakan energi yang cukup besar. Oleh karena itu, akan dilakukan penelitian pada 
bangunan kantor yang telah beroperasi dan membutuhkan efisiensi dengan memaksimalkan potensi tanpa melakukan perubahan yang cukup besar. Salah satu cara tanpa melakukan perubahan yang memakan biaya besar adalah dengan penzoningan ulang kantor sewa agar penggunaan AC dan pencahayaannya jadi minimal.

Kantor Summarecon yang berada di Serpong-Jakarta merupakan salah satu bangunan kantor bertingkat banyak yang berfungsi sebagai kantor pengelola dan kantor sewa. Bangunan ini direncanakan oleh pemilik agar menjadi image Sumarrecon yang sudah hemat energi. Oleh karena itu, arsitek perencana bangunan ini sudah melakukan perancangan bangunan hemat energi, namun untuk memaksimalkan efisiensi energi dibutuhkan perancangan interior hemat energi.

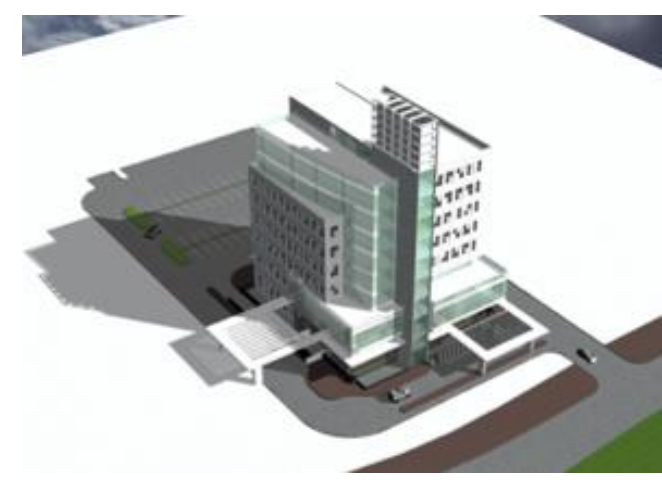

Gambar 1. Bird Eye View Summarecon Office Sumber: Budi Kusuma, 2008

Penelitian dilakukan dengan pendataan mengenai akumulasi panas yang berasal dari luar bangunan dengan perhitungan OTTV dan yang terdapat di dalam bangunan sendiri. Data ini dianalisis untuk mengetahui beban $\mathrm{AC}$ atau cooling load yang dibutuhkan di setiap jam sepanjang hari. Untuk pencahayaan alami dilakukan pendataan pergerakan matahari terhadap bangunan dengan menggunakan Sun Path dan jenis serta tipe jendela untuk mengetahui pemetaan cahaya alami yang masuk ke dalam bangunan.

Berdasarkan data sun path akan dilakukan perancangan zoning yang berkaitan dengan zoning pencahayaan alami. Hasil perhitungan cooling load akan didapatkan besarnya kapasitas AC yang tepat, dan sebagai masukan untuk manajemen bangunan untuk mengatur temperatur atau timer AC. Dengan masukan yang berkaitan dengan pencahayaan dan AC diharapkan dapat memaksimalkan perancangan gedung dalam melakukan efisiensi energi. Dan dapat pula dipergunakan untuk bangunan lain yang ingin melakukan efisiensi energi meskipun bangunannya belum direncanakan hemat energi. 


\section{METODE PENELITIAN}

Langkah penelitian dibagi menjadi 2 tahap utama, yaitu:

1. Mendapatkan data studi tentang Summarecon Office berupa gambar tampak bangunan, material bangunan dan aktivitas serta peralatan elektronik yang dipergunakan.

2. Analisis berupa perhitungan mengenai energi yang dipergunakan, berupa panas selubung (OTTV), beban pendinginan atau cooling load (CLTD) untuk mengetahui penyebab panas terbesar dalam bangunan, dan analisis pergerakan matahari (Sun Path) untuk mengetahui area bangunan yang terkena sinar matahari setiap hari selama jam kantor.

3. Setelah mendapatkan data mengenai area atau bagian penyumbang panas dalam gedung, akan didapatkan masukan-masukan untuk perencanaan ulang interior bangunan melalui perubahan zoning penggunaan ruang, zoning area yang membutuhkan isolasi panas, zoning saklar lampu dan data pendinginan untuk mengatur kapasitas, suhu dan timer AC.

A. Pengumpulan data

Untuk menghitung panas dari selubung bangunan, dibutuhkan data:

- Data material fasade berupa nilai transmitan atau U Value

- Gambar bangunan (denah, tampak, potongan dan detil tampak)

- Arah hadap bangunan dan koordinat bangunan.

Untuk menghitung cooling load dibutuhkan data:

- Data iklim berdasarkan garis lintang posisi bangunan

- Data peralatan sumber panas dalam bangunan

- Data tentang akumulasi manusia

- Data tentang jam kerja dan aktivitas yang dilakukan

- Data mengenai material fasade (nilai transmitan)

- Data luas bangunan

- Gambar bangunan (denah, tampak, potongan, detil tampak).

Untuk menbuat Sun Path dibutuhkan data:

- Tiga dimensi bangunan berupa sketchup atau $3 \mathrm{dmax}$

- Garis lintang posisi bangunan

- Bangunan sekitar.

Untuk mengukur pencahayaan alami, dibutuhkan data: 
- Gambar bangunan, berupa denah dan potongan di posisi jendela.

B. Analisis data

Analisis yang dilakukan dengan menggunakan metode berikut ini:

- OTTV (Overall Thermal Transfer Value)

- CLTD (Cooling Load Thermal Difference)

- Sunpath

- Grafis pencahayaan alami.

Bangunan perkantoran dibutuhkan efisiensi energi bangunan, akan tetapi tidak dapat mengurangi tingkat kenyamanan bangunan karena pada akhirnya akan berpengaruh kepada produktivitas kerja. Kenyamanan sendiri terdiri dari suhu, kelembapan udara, kecepatan angin, radiasi, temperatur permukaan, aktivitas manusia dan pakaian yang dipergunakannya. Bangunan perkantoran bertingkat banyak tentunya menggunakan bantuan AC untuk mengkondisikan udaranya. Namun, agar AC yang bekerja efisien maka perlu diperhatikan penyebab panas di dalam bangunan.

\section{Penyebab Panas dalam Bangunan}

Penyebab panas dalam bangunan terdiri dari faktor eksternal dan internal bangunan itu sendiri, karena tanpa disadari faktor tersebut memberikan kontribusi panas yang menjadi besarnya beban penyejukan AC. Hal ini perlu diketahui, karena akan berpengaruh dalam perencanaan penggunaan AC.

\section{Faktor Eksternal}

Udara luar yang memiliki suhu udara tidak nyaman, jika dibiarkan masuk ke dalam ruangan akan mengakibatkan suhu udara dalam ruangan ikut naik. Oleh karena itu, untuk menciptakan suhu udara yang nyaman dalam ruang dibutuhkan AC, bahkan jika suhu udara yang terdapat dalam ruangan butuh penurunan suhu cukup banyak maka beban AC akan semakin besar. Maka suhu udara luar pun harus diperhatikan, apakah sudah memenuhi syarat kenyamanan atau belum, sehingga berpengaruh pada perencanaan ventilasi alami.

Keadaan iklim didasarkan pada penelitian di Stasiun Geofisika Kelas I Tangerang yaitu berupa data temperatur (suhu) udara, kelembaban udara dan intensitas matahari, curah hujan dan rata-rata kecepatan angin. Temperatur udara rata-rata berkisar antara 23,5-32,6 
${ }^{\circ} \mathrm{C}$, temperatur maksimum tertinggi pada bulan Oktober yaitu $33,9{ }^{\circ} \mathrm{C}$ dan temperatur minimum terendah pada bulan Agustus dan September yaitu $22,8^{\circ} \mathrm{C}$. Rata-rata kelembaban udara dan intensitas matahari sekitar 78,3 \% dan 59,3\%. Keadaan curah hujan tertinggi terjadi pada bulan Februari yaitu $486 \mathrm{~mm}$, sedangkan rata-rata curah hujan dalam setahun adalah 177,3 mm. Hari hujan tertinggi pada bulan Desember dengan hari hujan sebanyak 21 hari. Rata-rata kecepatan angin dalam setahun adalah $3,8 \mathrm{~m} /$ detik dan kecepatan maksimum 12,6 m/detik.

\section{Panas dari Pelingkup Bangunan}

Pelingkup bangunan dapat memberikan panas dalam ruangan, melalui proses konduksi, konveksi maupun radiasi. Jadi dalam pemilihan bahan baik satu jenis maupun majemuk, perlu diperhitungkan nilai dari konduktan, transmitan. Material yang mengkilap, silver akan memantulkan panas dan hampir keseluruhan benda mentransmisikan energi elektromagnetik dengan panjang gelombang tertentu ketika mengabsorbsi atau merefleksikan.

Faktor lain yang mempengaruhi perpindahan panas dari luar bangunan ke dalam bangunan melalui suatu bahan pelingkup bangunan, yaitu time lag. Time lag yaitu waktu yang dibutuhkan oleh suatu bahan untuk mengumpulkan panas dan menghantarkan panas ke sisi yang memiliki suhu lebih rendah. Contoh time lag yang ekstrim yaitu pada bahan spon, bahan ini menyerap air, lalu setelah maksimal air akan mengalir ke sisi yang lainnya. Begitu pula pada penyerapan panas pada bahan bangunan, setiap bahan memiliki waktu tertentu untuk mengisi panas lalu menghantarkan ke dalam ruangan. Semakin tebal suatu bahan semakin lama waktu yang dibutuhkan untuk menimbun sejumlah kalor sampai penuh, dan semakin lama juga jarak waktu agar sisi dingin bersuhu sama dengan sisi yang panas.

Tabel 1. Time Lag Bahan Bangunan

\begin{tabular}{|l|c|c|c|}
\hline Bahan & \multicolumn{2}{|c|}{$\begin{array}{c}\text { Tebal } \\
\text { Inch } \\
\text { (+ cm) }\end{array}$} & $\begin{array}{c}\text { Selang waktu } \\
\text { (time lag) jam, } \\
\text { menit }\end{array}$ \\
\hline Batu bata & 9 & 23 & 7.30 \\
\cline { 2 - 5 } & 4.5 & 1.5 & 3.45 \\
\hline beton & 6 & 15 & 4.20 \\
\hline
\end{tabular}




\begin{tabular}{|l|l|l|l|}
\hline \multirow{2}{*}{} & 4 & 10 & 2.55 \\
\cline { 2 - 4 } & 2 & 5 & 1.30 \\
\hline
\end{tabular}

Sumber: Mangunwijaya, 1980

\section{Faktor Internal}

Salah satunya yang menyebabkan panas pada dalam ruangan, salah satunya adalah peralatan yang digunakan. Tanpa disadari sebagian besar peralatan yang digunakan dalam suatu gedung, justru akan mengeluarkan panas dan mengakibatkan temperatur dalam ruangan naik. Contoh peralatan yang menimbulkan panas, yaitu: komputer, mesin fotokopi, server,dan lain-lain.

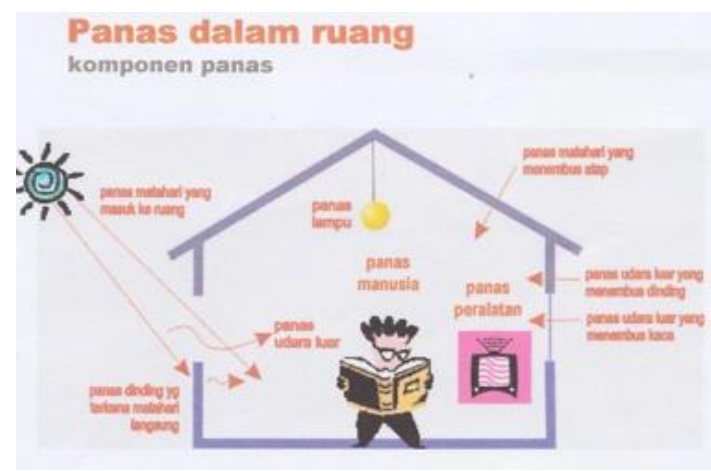

Gambar 2. Panas yang masuk ke dalam ruangan Sumber: Satwiko, 2004

\section{Energi AC}

Secara umum pengertian energi $A C$ itu sendiri berasal dari besarnya beban kalor yang akan dikondisikan oleh AC, dalam satuan yang dikenal dengan BTUH (British Thermal Unit Hour). BTUH di lapangan sering disebut dengan 1 ton pendinginan, yaitu daya pendinginan yang dihasilkan oleh 1 ton es padat saat mencair dalam waktu 24 jam. 1 ton penyejukan ini setara dengan 12.000 BTUH dan setara dengan 3.516 W (sekitar 3,5 kW). Dan nilai watt inilah yang dijadikan biaya dari penggunaan daya listrik.

Energi listrik yang digunakan pada AC adalah untuk menggerakkan kompresor, yang kemudian digunakan untuk menggerakkan siklus refrigeran seperti yang telah dijelaskan di atas. Jadi jika selisih suhu antara suhu yang diinginkan dan keadaan suhu ruang besar, maka akan menambah beban dari kompresor untuk menggerakkan siklus refrigerant lama lagi sehingga tentunya listrik yang dibutuhkan pun akan semakin besar. 
Jadi yang menjadi permasalahan dalam penggunaan AC yaitu borosnya energi. Yang menjadikan AC menjadi boros energi karena tidak adanya kesinambungan dengan desain bangunannya. Misalnya, pada perencanaan bangunan tidak dipikirkan mengenai penggunaan AC atau arsitek yang kurang peka dalam memilih material atau bahan bangunan yang dipakai.

\section{Teknik Efisiensi Energi Air Conditioning}

Teknik pengurangan energi AC berarti mengurangi kalor atau panas yang masuk ke dalam ruangan, sehingga desain dari bangunan membutuhkan perhatian mengenai pengendalian panas yang masuk ke dalam ruangan interior bangunan.

Yang perlu dipertimbangkan adalah (Mangunwijaya, 1980: 128):

- Selisih suhu, antara sisi panas dan sisi dingin, serta selisih suhu dengan ruangan yang terletak di sebelahnya.

- Kelembapan udara, erat kaitannya dengan kenyamanan suatu ruangan. Misalnya: meskipun udara sejuk tetap akan tidak nyaman jika bau busuk akibat kelembapan tinggi.

- Karena persyaratan kenyamanan dari setiap ruangan berbeda, maka pemilihan bahan pelingkupnya juga akan berbeda.

- Dalam pemilihan bahan yang cocok dengan kenyamanan termal, juga perlu diperhatikan bagaimana dengan kondisi akustik yang akan terjadi dengan pemilihan bahan tersebut. Semakin kecil berat jenis suatu benda $(\rho)$ semakin kecil juga panas yang masuk, akan tetapi isolasi bunyi menjadi buruk.

- Semakin tebal bahan pelingkup panas, semakin lama juga waktu yang dibutuhkan untuk menimbun sejumlah kalor sampai penuh dan semakin lama pula waktu untuk memanaskan sisi dingin. Waktu yang dibutuhkannya disebut time lag (selang waktu).

\section{Penghematan Energi Pencahayaan}

Untuk melakukan efisiensi energi dalam penggunaan cahaya di dalam bangunan, harus memperhatikan beberapa hal berikut:

- memanfaatkan cahaya alami efektif yang masuk bangunan

- meletakkan lampu sesuai dengan tatanan interior di bawahnya

- menentukan tingkat terang yang sesuai

- memastikan lampu dipergunakan pada saat dibutuhkan, misalkan pada saat tingkat terang di dalam bangunan berkurang atau mendung, malam hari, pada saat ruang dipergunakan 
- Menggunakan bahan interior yang memiliki nilai reflektan tinggi agar cahaya lampu dapat terpancar maksimal ke bidang kerja

- Mengelompokkan zoning saklar sesuai dengan zoning cahaya alami efektif yang masuk agar sebagian lampu dapat dimatikan ketika terang, angin dalam kondisi tidak berawan.

\section{PEMBAHASAN}

Untuk merencanakan penghematan energi, dilakukan analisis awal kondisi bangunan. Analisis dibagi menjadi dua bagian sesuai dengan sumber panas:

1. Faktor eksternal

Faktor eksternal bangunan, akan dilakukan perhitungan OTTV (Overall Thermal Transfer Value) untuk mengetahui besarnya panas yang menembus melalui selubung bangunan.

Dengan OTTV dapat ditentukan bangunan tersebut hemat energi.

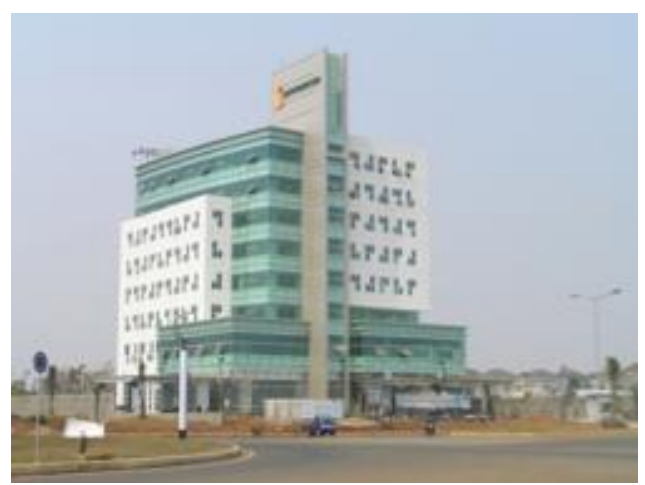

Gambar 3. Tampak Depan bangunan Summarecon Office Sumber: Dok. Budi Kusuma

Untuk memperhitungkan OTTV diperlukan data transmitan atau $U$ value dari material selubung bangunan yang dipergunakan

Tabel 2. Nilai transmitan material fasade bangunan

\begin{tabular}{|l|l|l|l|}
\hline No & Bagian bangunan & Material bangunan & $\begin{array}{l}\text { U Value } \\
\left(\mathrm{Watt} / \mathrm{m}^{2}\right)\end{array}$ \\
\hline 1 & dinding & precast beton & 1.08 \\
\hline 2 & jendela & Kaca: stopsol green & 0.1879 \\
\hline
\end{tabular}



Summarecon Office, Jakarta

\begin{tabular}{|l|l|l|}
\hline & Frame: alumunium & \\
\hline \multicolumn{3}{|c|}{ Sumber: Dok Pribadi }
\end{tabular}

Berdasarkan data di atas dilakukan perhitungan OTTV dan menghasilkan data berikut:

Tabel 3. Grafik Besar Nilai OTTV tiap sisi bangunan

\begin{tabular}{|c|c|c|c|}
\hline & $\begin{array}{l}\text { OTTV } \\
\text { watt/m2 }\end{array}$ & $\begin{array}{l}\text { OTTV } \\
\text { standar } \\
\text { watt/m² }\end{array}$ & kategori \\
\hline $\begin{array}{l}\text { Tampak } \\
\text { depan }\end{array}$ & 21.6 & $\leq 45$ & $\begin{array}{l}\text { Hemat } \\
\text { energi }\end{array}$ \\
\hline Tampak kiri & 36.3 & & $\begin{array}{l}\text { Hemat } \\
\text { energi }\end{array}$ \\
\hline $\begin{array}{l}\text { Tampak } \\
\text { belakang }\end{array}$ & 24.5 & & $\begin{array}{l}\text { Hemat } \\
\text { energi }\end{array}$ \\
\hline $\begin{array}{l}\text { Tampak } \\
\text { kanan }\end{array}$ & 26.1 & & $\begin{array}{l}\text { Hemat } \\
\text { energi }\end{array}$ \\
\hline Rata-rata & 18.2 & & $\begin{array}{l}\text { Hemat } \\
\text { energi }\end{array}$ \\
\hline
\end{tabular}

Sumber: Dok. Pribadi

Berdasarkan data analisis di atas, bangunan ini memiliki nilai OTTV $18,2 \mathrm{watt} / \mathrm{m}^{2}$, artinya bangunan ini tergolong hemat energi karena nilai rata-rata bangunannya di bawah 45 watt $/ \mathrm{m}^{2}$. Angka ini juga berarti panas matahari yang tembus melalui material fasade bangunan ke dalam interior sangat kecil dan tidak berdampak banyak terhadap pemanasan ruang atau penambahan cooling load AC. Oleh karena itu, panas atau cooling load yang berasal dari penetrasi material fasade diabaikan, sehingga yang diperhitungkan hanya cooling load yang berasal dari internal saja.

Panas yang berasal dari internal yaitu akumulasi manusia, peralatan elektronik yang dipergunakan dan lampu. Peralatan elektronik yang menimbulkan panas dapat dikelompokkan dan diisolasi agar panasnya tidak menyebar ke area yang akan disejukkan, untuk lampu dapat diganti dengan lampu yang tidak menimbulkan panas, seperti CFL atau led. Pemanfaatan cahaya alami yang masuk juga berarti akan mengurangi jumlah lampu pada siang hari sehingga mengurangi panas internal. 
Pergerakan sinar matahari merupakan bagian dari faktor eksternal untuk mengetahui area yang terkena sinar matahari. Data ini dapat dimanfaatkan untuk pembuatan zoning ruang yang memanfaatkan cahaya alami. Metode yang dipergunakan adalah Sun Path. Metode ini bermanfaat untuk mengetahui pergerakan dan pembayangan sinar matahari sehari penuh setiap jamnya. Berikut hasil analisis dengan menggunakan sunpath:

\section{Percobaan 1}

Dilakukan jam 8 pagi, sebagai jam awal kantor beroperasi, AC dan lampu dinyalakan.

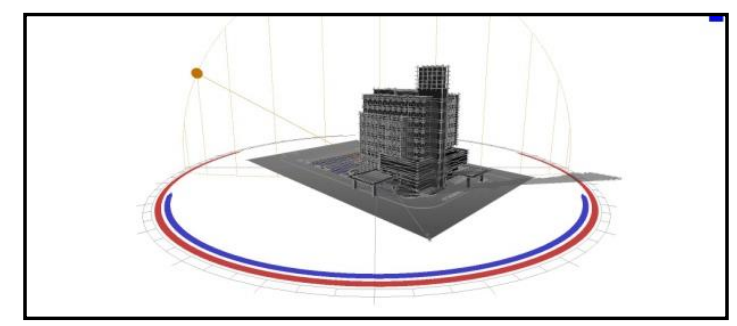

Gambar 4. Pergerakan matahari terhadap gedung pada jam 8pagi

Sumber: Dok. Pribadi

Pada jam 8.00 pagi, area bangunan yang terkena penetrasi sinar matahari, yaitu pada bagian kiri bangunan antara lantai 1 hingga lantai 5. Namun area yang terkena penetrasi sinar matahari terbesar pada area kiri bangunan lantai 1, maka sebaiknya dimanfaatkan untuk fungsi yang tidak membutuhkan konsentrasi tinggi atau ruang yang dipergunakan di atas jam 11 siang.

\section{Percobaan 2}

Dilakukan jam 9.00 pagi pada saat kantor beroperasi, AC dan lampu dinyalakan.

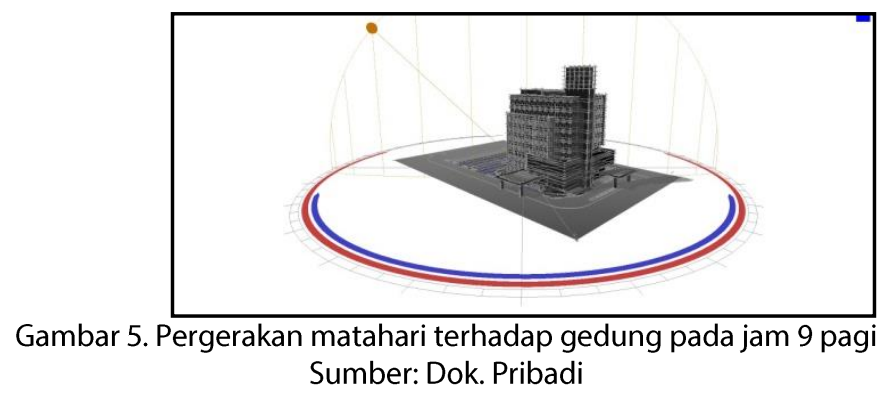

Pada jam 9.00 pagi area kiri bangunan hampir seluruhnya terkena penetrasi sinar matahari, akan tetapi area paling panas terdapat di lantai 2. Sebaiknya area ini dihindari hingga jam 11. 


\section{Percobaan 3}

Dilakukan jam 10.00 pagi pada saat kantor beroperasi, AC dan lampu dinyalakan.

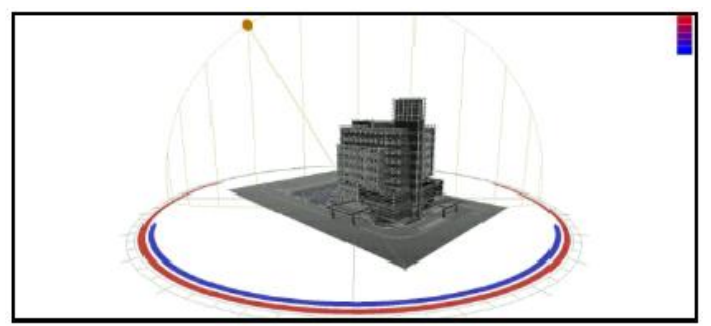

Gambar 1. Pergerakan matahari terhadap gedung pada jam 10 pagi Sumber: Dok. Pribadi

Pada jam 10.00 pagi area kiri bangunan hampir seluruhnya terkena penetrasi sinar matahari, akan tetapi area paling panas terdapat di lantai 4. Sebaiknya area ini dihindari hingga jam 11.

\section{Percobaan 4}

Dilakukan jam 11.00 pagi pada saat kantor beroperasi, AC dan lampu dinyalakan.

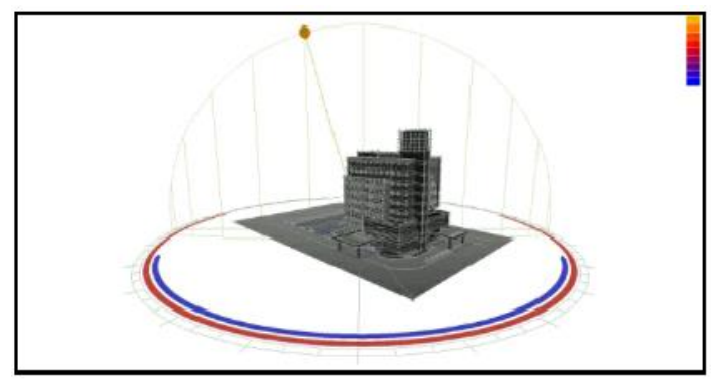

Gambar 2. Pergerakan matahari terhadap gedung pada jam 11 siang Sumber: Dok. Pribadi

Pada saat jam 11.00 matahari sudah bergerak ke arah atas bangunan sehingga sinar matahari tidak akan masuk secara langsung. Semua lantai di area kiri bangunan sudah aman dipergunakan tanpa harus menambah kapasitas $A C$ atau mengurangi kenyamanan.

\section{Percobaan 5}

Dilakukan jam 12 siang pada saat kantor beroperasi, AC dan lampu dinyalakan.

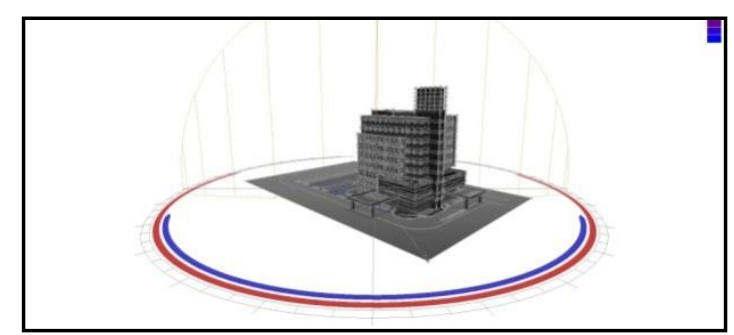

Gambar 3. Pergerakan matahari terhadap gedung pada jam 12 siang Sumber: Dok. Pribadi 
Pada saat jam 12.00 siang, matahari tepat berada di atas bangunan. Jadi semua area bangunan dapat dipergunakan tanpa harus menambah kapasitas $A C$ atau mengurangi kenyamanan.

\section{Percobaan 6}

Dilakukan jam 1 siang pada saat kantor beroperasi, AC dan lampu dinyalakan.

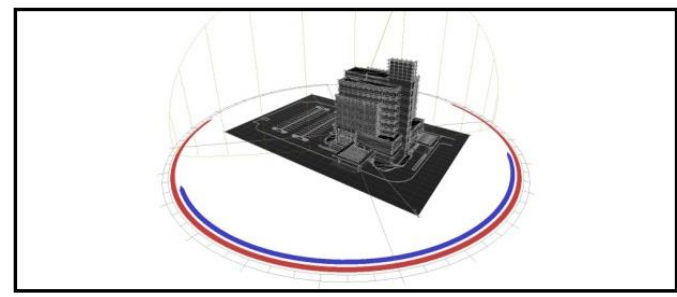

Gambar 4. Pergerakan matahari terhadap gedung pada jam 1 siang Sumber: Dok. Pribadi

Pada jam 13.00 penetrasi sinar matahari maksimum pada lantai 10 di area kanan bangunan. Area ini sebaiknya dihindari hingga jam 16.00 agar tidak menambah kapasitas AC atau mengurangi kenyamanan.

\section{Percobaan 7}

Dilakukan jam 2 siang pada saat kantor beroperasi, AC dan lampu dinyalakan.

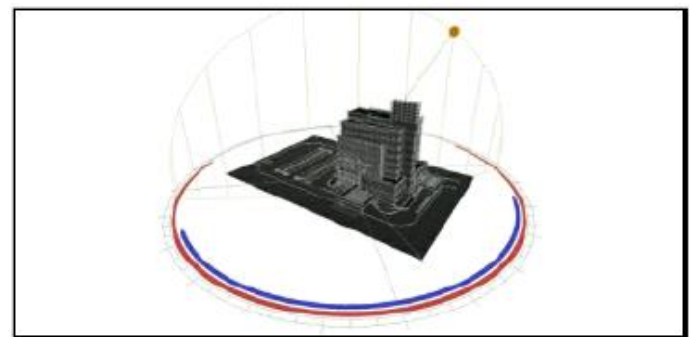

Gambar 5. Pergerakan matahari terhadap gedung pada jam 2 siang Sumber: Dok. Pribadi

Pada jam 14.00 pergerakan matahari tidak begitu signifikan. Penetrasi sinar matahari maksimum masih sama dengan jam sebelumnya, yaitu pada lantai 10 di area kanan bangunan. Area ini sebaiknya dihindari hingga jam 16.00 agar tidak menambah kapasitas $A C$ atau mengurangi kenyamanan.

\section{Percobaan 8}

Dilakukan jam 15.00 pada saat kantor beroperasi, AC dan lampu dinyalakan. 

Summarecon Office, Jakarta

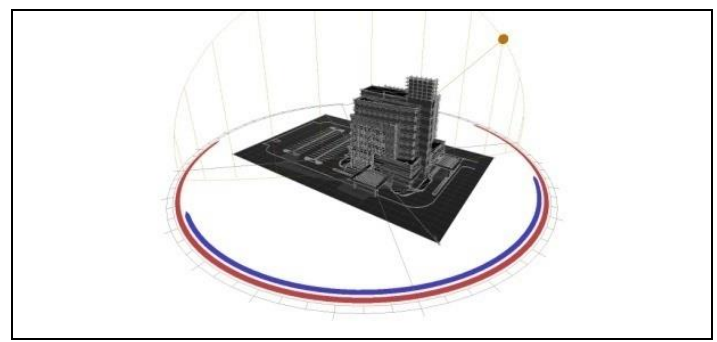

Gambar 6. Pergerakan matahari terhadap gedung pada jam 3 sore Sumber: Dok. Pribadi

Pada jam 15.00 sinar matahari tepat menyinari lantai 10 secara maksimum. Jadi area ini sebaiknya tidak dipergunakan, karena hampir 3 jam matahari menyinari area ini secara terus menerus. Jika dipaksakan maka akan menambah kapasitas atau cooling load yang cukup banyak.

\section{Percobaan 9}

Dilakukan jam 16.00 pada saat kantor beroperasi, AC dan lampu dinyalakan.

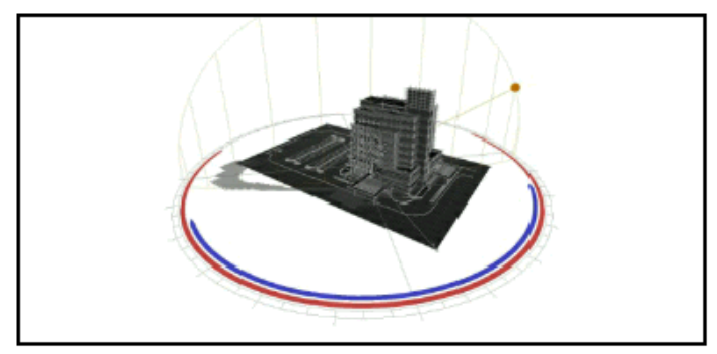

Gambar 7. Pergerakan matahari terhadap gedung pada jam 4 sore Sumber: Dok. Pribadi

Pada jam 16.00 area yang terkena sinar matahari maksimum yaitu lantai 7 pada sisi kanan bangunan. Namun panas yang terjadi pada area ini hanya berkisar 1 jam, sehingga masih dapat ditoleransi atau dapat diatasi dengan internal blind.

\section{Percobaan 10}

Dilakukan jam 17.00 pada saat kantor beroperasi, AC dan lampu dinyalakan.

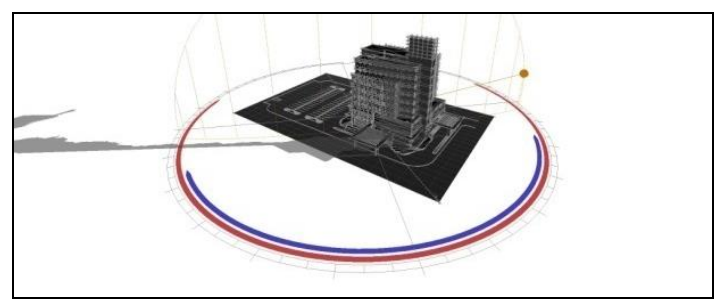

Gambar 8. Pergerakan matahari terhadap gedung pada jam 5 sore Sumber: Dok. Pribadi 
Pada jam 5 sore area yang terkena sinar matahari maksimum yaitu pada lantai 2 area kanan bangunan. Panas yang berlangsung hanya berkisar 1 jam, sehingga masih dapat ditoleransi seperti lantai sebelumnya.

\section{Percobaan 11}

Dilakukan jam 18.00 pada saat kantor beroperasi, AC dan lampu dinyalakan.

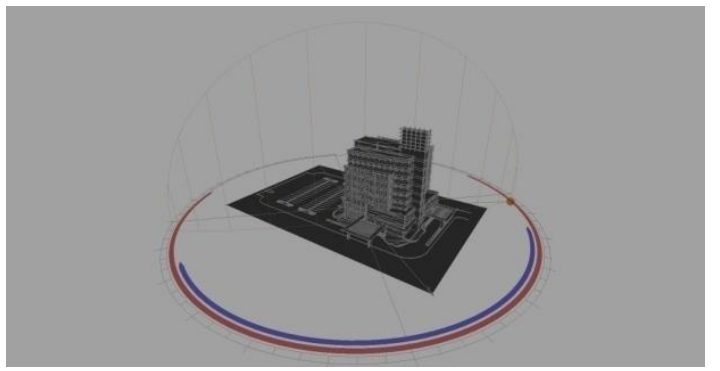

Gambar 9. Pergerakan matahari terhadap gedung pada jam 6 sore Sumber: Dok. Pribadi

Pada jam 18.00, intensitas sinar matahari sudah sangat menurun, sehingga sudah dapat diabaikan. Hanya pada saat matahari bersinar panjang, maka lantai 1 area kanan bangunan akan terkena sinar matahari maksimum. Pada jam ini aktivitas kantor juga sudah menurun jadi dapat sepenuhnya diabaikan.

\section{Faktor Internal}

Dalam penelitian ini, metoda CLTD (Cooling Load Thermal Difference) dipakai untuk memperhitungkan panas internal. CLTD adalah salah satu perhitungan untuk mengetahui besarnya beban pendinginan di dalam bangunan akibat akumulai panas dari eksterior (panas yang masuk melalui fasade) dan panas interior (akibat beban penggunaan seperti: alat elektronik, manusia, lampu, dan lain-lain). Selain besarnya beban pendinginan, pada grafik ini akan diketahui juga besarnya beban pendinginan puncak pada jam-jam tertentu, jadi dengan adanya grafik ini akan memberikan masukan pada manajemen bangunan untuk melakukan pengaturan penggunaan AC agar lebih hemat energi. Pengaturan dapat dilakukan dengan mematikan sebagian zoning AC pada jam-jam tertentu pada saat beban pendinginannya kecil.

Grafik CLTD ini diperhitungkan 4 bulan yang mewakili Maret, Juni, September, dan Desember karena sebagai bulan-bulan kritis yang mewakili setiap pergerakan panas matahari yang akan berpengaruh pada intensitas panas matahari. Dalam perhitungan CLTD, 

Summarecon Office, Jakarta

diasumsikan setiap lantai menggunakan peralatan elektronik 2-3 komputer, 1 mesin fotokopi, 1 ruangan pantry, dan jumlah manusia 15- 20 orang.
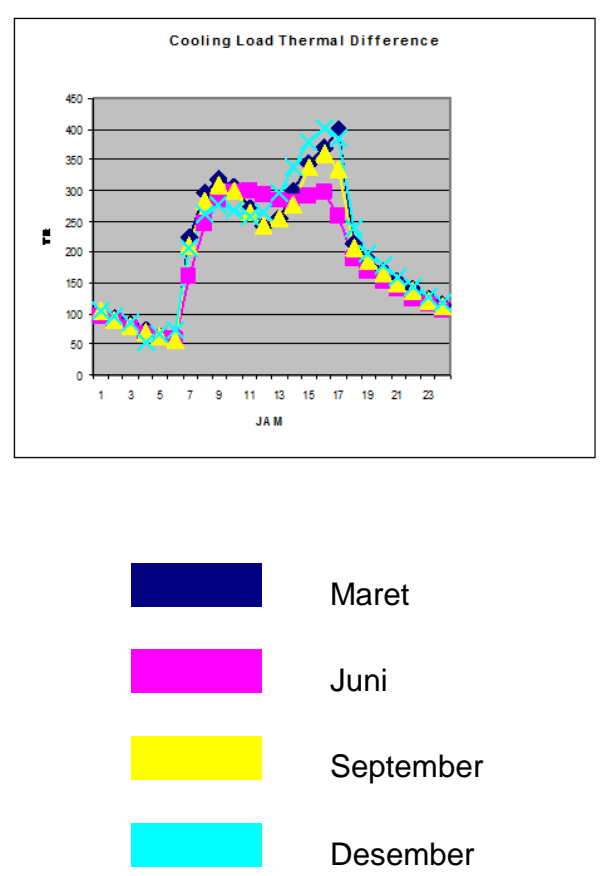

\section{Gambar 10. Cooling load Sumber: Dok. pribadi}

Berdasarkan grafik CLTD di atas, beban puncak cooling load bangunan ini berada pada jam 16.00 hingga 18.00. Jadi pengelola bangunan dapat mengatur setting AC sebagai berikut:

Tabel 4. Setting suhu dan pengaturan kapasitas AC

\begin{tabular}{|l|l|l|l|}
\hline No & Jam & $\begin{array}{l}\text { AC mulai } \\
\text { dijalankan } \\
\text { sebagian }\end{array}$ & minimum \\
\hline 1 & Pk 8.00 & $\begin{array}{l}\text { AC mulai } \\
\text { dijalankan } \\
\text { semua }\end{array}$ & sedang \\
\hline 2 & Pk 9.00-10.00 & $\begin{array}{l}\text { AC mulai } \\
\text { dijalankan } \\
\text { semua }\end{array}$ & minimum \\
\hline 3 & Pk 10.00-14.00 & $\begin{array}{l}\text { AC mulai } \\
\text { dijalankan } \\
\text { semua }\end{array}$ & maksimum \\
\hline 4 & Pk 14.00-17.00 & & \\
\hline
\end{tabular}

Sumber: Dok. Pribadi 


\section{PENUTUP}

Berdasarkan penelitian yang telah dilakukan, bangunan ini memiliki sumber panas terbesar berasal dari internal atau berasal dari interior dan aktivitas bangunan. Hal ini dinyatakan dengan nilai OTTV dibawah 45 watt/m2, sehingga transfer panas yang berasal dari luar bangunan yang ditransmisikan melalui fasade bengunan sangat minim. Berdasarkan metoda CLTD didapatkan hasil yang cukup tinggi berasal dari interior bangunan dan didapatkan panas maksimum antara jam 14.00- 17.00.. Upaya yang dilakukan untuk mengurangi panas yang berasal dari interior dapat dilakukan beberapa hal berikut ini:

- Pengelompokan ruang yang menjadi sumber panas dalam interior (misal: ruang mesin, mesin fotocopy, komputer)

- Menggunakan lampu yang tidak panas dan tentunya meminimalkan penggunaan lampu.

- Zoning ruang dapat disesuaikan dengan zoning pergerakan cahaya, agar minimum dalam penggunaan lampu.

- Tempatkan area yang membutuhkan kenyamanan tinggi pada area yang tidak terkena panas.

Berikut beberapa hal yang dapat mengefisiensikan energi bangunan khususnya dalam penggunaan $\mathrm{AC}$ dan pencahayaan:

- Dilakukan manajemen energi dengan pengaturan angka maksimal temperatur dan lampu, sehingga AC dan lampu mati setelah jam operasional, lampu outdoor dinyalakan hanya pada event khusus saja.

- Renewable energy: energi listrik yang dipergunakan adalah energi listrik tenaga gas sehingga listrik lebih konstan dan pada saat ini masih dalam jumlah yang banyak di Indonesia.

- Zoning saklar lampu yang dapat dimatikan ketika sinar matahari masuk

KETERANGAN:

: pencahayan alami yang efektif,
tidak membutuhkan bantuan
pencahayaan buatan pada siang
hari
$\begin{aligned} & \text { pencahayaan alami sedang, } \\ & \text { membutuhkan } \\ & \text { pencahayaan buatan yang minimal } \\ & \text { bantuan }\end{aligned}$
$\begin{aligned} & \text { pencahayaan alami minimal, } \\ & \text { membutuhkan } \\ & \text { pencahayaan buatan }\end{aligned}$


Serat Rupa Journal of Design, September 2016, Vol.1, No.2: 355-375

Tantri Oktavia - Pengaturan Ulang Zoning Ruang Untuk Mengetahui Efisiensi Beban Dan Pencahayaan Pada Summarecon Office, Jakarta

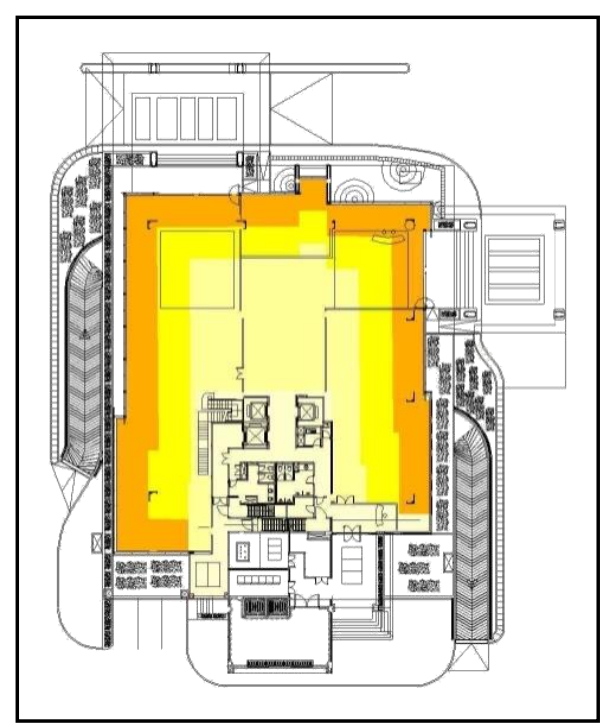

Gambar 20. Daylighting on $1^{\text {st }}$ floor Sumber: Dok. Pribadi

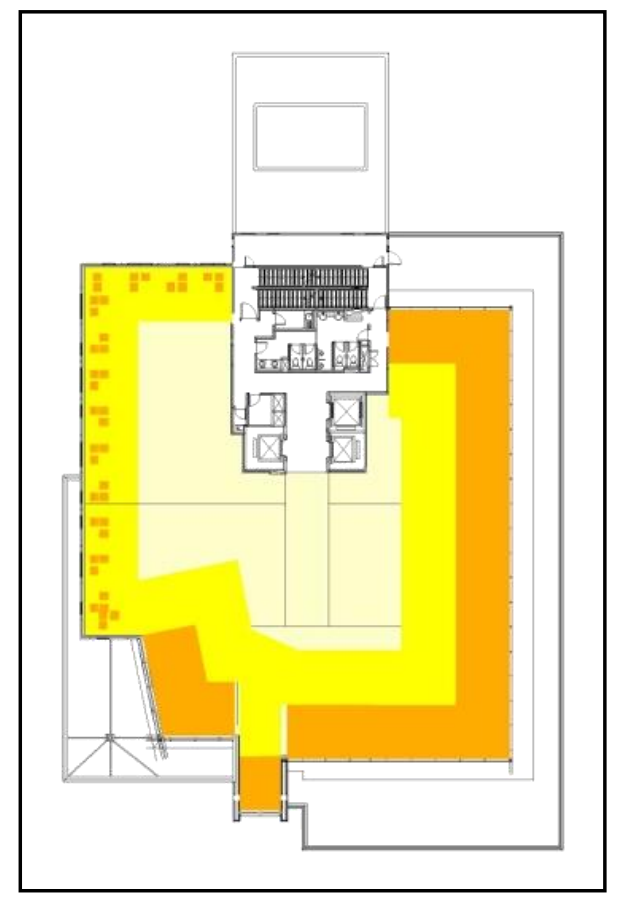

Gambar 21. Daylighting on $2^{\text {ed }}$ floor Sumber: Dok. Pribadi 

Summarecon Office, Jakarta

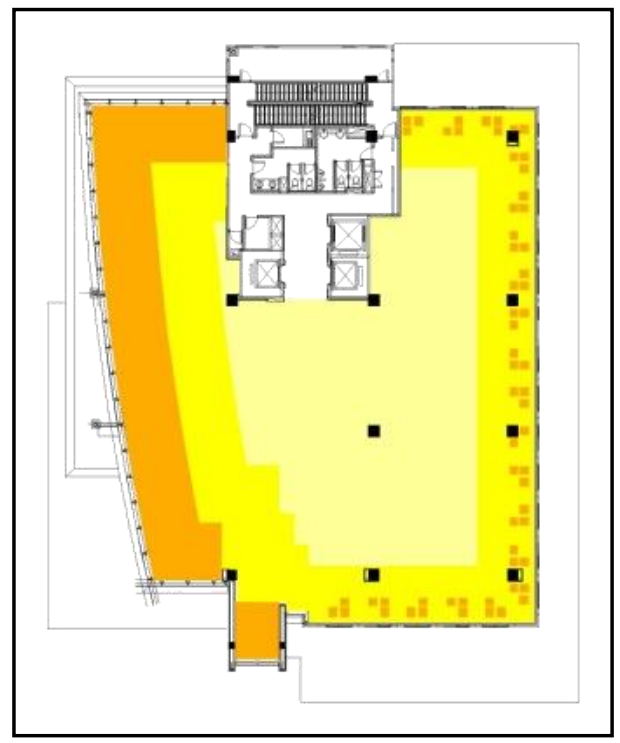

Gambar 22. Daylighting on $3^{\text {rd }}$ floor Sumber: Dok. Pribadi

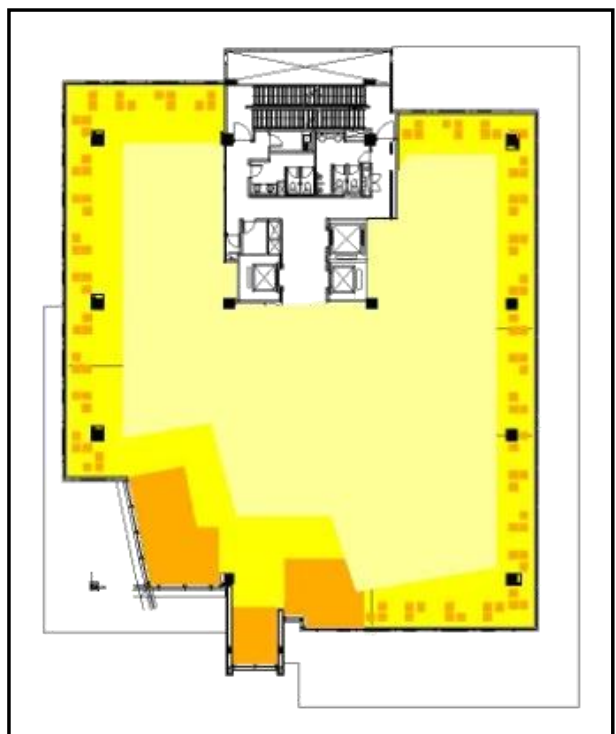

Gambar 23. Daylighting on $5^{\text {rd }}$ floor Sumber: Dok. Pribadi

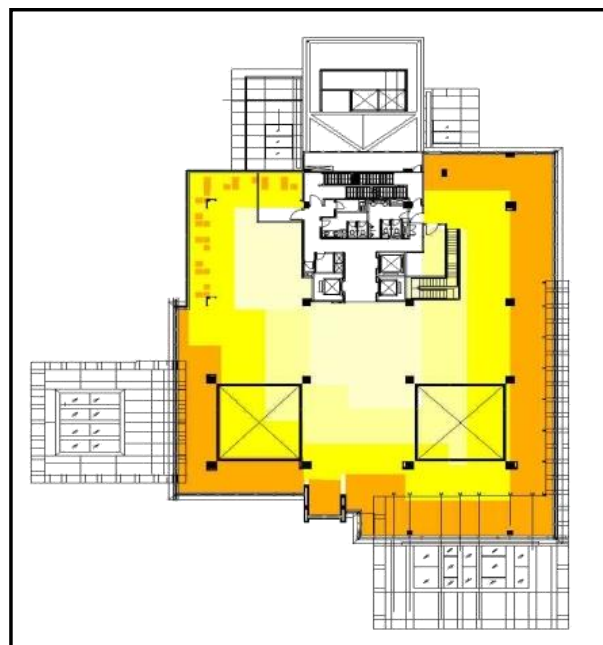


Perencanaan interior pada bangunan yang sudah memperhatikan desain hemat energi, akan menambah efisiensi bangunan sebesar $38 \%$. Beberapa hal yang dapat dilakukan:

- Membuat zoning berdasarkan pergerakan matahari atau sun path. Berdasarkan sun path dapat diketahui area mana saja yang mengalami panas pada jam-jam tertentu. Area panas ini diusahakan untuk dihindari agar penggunaan AC dapat minimal. Jika terpaksa dipergunakan, maka perlu melakukan treatment fasade bangunan lebih seperti material.

- Membagi area AC sesuai dengan zoning ruang interior agar AC maksimal dan hanya dijalankan pada area yang dibutuhkan saja.

- Pengaturan zoning lampu dibuat berdasarkan perhitungan cahaya alami yang masuk. Jadi pada siang hari kondisi normal, lampu dapat dimatikan sebagian mengikuti zoning masuknya cahaya matahari.

- Pengelompokan area yang banyak menggunakan peralatan-peralatan yang mengeluarkan panas, cukup membantu berkurangnya penyebab panas dalam bangunan.

- Meletakkan ruang yang lebih bertoleransi terhadap panas sebagai buffer.

Berikut ini beberapa hal yang dapat dilakukan interior untuk mengurangi penggunaan energi. Beberapa hal lagi yang dapat memaksimalkan adalah manajemen bangunan seperti penggunaan lift yang dibagi lantainya sesuai dengan intensitasnya dan hubungan ruangnya, pemilihan jenis lampu yang hemat energi, penggunaan saklar otomatis, membatasi penggunaan listrik, pengaturan setting suhu, dan lain-lain.

\section{DAFTAR PUSTAKA}

Bradshaw, Vaughn, P.E. (1993). Building Control Systems. New York: John Willey \& Sons, Inc. Guy. R. King. (1965). Basic Air Conditioning. Illinois: Nickerson \& Collins CO. Hornby, A.F. (1995). Advanced Learner's English Dictionary. London: Oxford University. Lechner, Norbert. (2001). Heating, Cooling, Lighting Design Methodes for Architects (second edition). USA: John Willey \& Sons, Inc.

Mangunwijaya, YB. (1980). Pasal-pasal Penghantar Fisika Bangunan. Jakarta: PT. Gramedia. Poerbo, Hantono. (1998). Utilitas Bangunan, Jakarta: Djambatan. Satwiko, Prasasto. (2004). Fisika Bangunan 1 (edisi 1). Yogyakarta: Penerbit ANDI. Satwiko, Prasasto. (2004). Fisika Bangunan 2 (edisi 1). Yogyakarta: Penerbit ANDI. 

Summarecon Office, Jakarta

Badan Standarisasi Nasional 2000 SNI 03-6197-2000: Konservasi energi pada sistem pencahayaan.

Badan Standarisasi Nasional 2001 SNI 03-2396-2001: Tata cara perancangan sistem pencahayaan alami pada bangunan gedung.

Hariadi, Tatang. Pengukuran Indeks Kenyamanan Termal dengan Menggunakan Predicted Mean Vote (PMV) dan Predicted Percentage of Dissatisfied (PPD). 